\title{
J111011
}

\section{高濃度ナノダイヤモンド含有無電解ニッケルめっき複合膜の合成 とそのトライボロジー特性}

\author{
田口 明徳 ${ }^{* 1}$, 木之下 博 ${ }^{* 2}$, 藤井 正浩 ${ }^{* 2}$ \\ Synthesis and tribological property of high density nanodiamond-electroless \\ nickel plating composite \\ Akinori TAGUCHI $^{* 1}$, Hiroshi KINOSHITA ${ }^{* 2}$, Masahiro FUJII ${ }^{* 2}$ \\ Okayama University, 3-1-1 Tsushimanaka, Kita-Ku, Okayama, 700-0080, Japan

\begin{abstract}
In this study, nanodiamond (ND)-electroless Ni plating composite coating was synthesized for high wear resistance and low friction. The ND-Ni plating composite coating was prepared from electroless Ni plating solution dispersing diamond nano particle (DNP) on S50C substrate. Heat treatment to increase hardness of electroless Ni plating was conducted in this coating. Tribological properties of the ND-Ni plating composite coating was investigated under three lubricant conditions (no lubrication, water lubrication and 1wt.\% DNP dispersion). Under the DNP dispersion, the friction coefficient of ND-Ni plating composite film and Ni plating coating were lower than other conditions. Severe wears after the friction tests were observed on the ND-Ni plating composite coating under no lubrication, however only small protrusion of the composite film tested under the DNP dispersion was worn.
\end{abstract}

Key Words : Diamond nano particle, electroless nickel plating

\section{1. 緒言}

ダイヤモンドナノ粒子（Diamond nano particle; DNP）は 4-6 nm サイズの極微粒子でありながらもダイヤモンド 結晶構造を有するため高硬度で, かつ低摩擦・低摩耗性を有しており, 潤滑材料として他にない優れた特性を備 えていると考吕れている.この特性を耐摩耗膜として用いられている無電解ニッケルめっきに加えることがで きるなら，両者の特性を兼ね備えた優れたトライボロジー特性を実現できる. 本研究では S50C 上に DNP-Ni 複 合めっき膜を施し, $1 \mathrm{~N}$ の荷重を加えて, 無潤滑, 水潤滑, DNP 分散液による潤滑の 3 条件で摺動試験を行い, それらのトライボロジー特性について調べた。ささらに，摺動痕を走查型電子顕微鏡(Scanning Electron Microscope; SEM)等を用いて調べた.

\section{2. 実験}

Fig.1 に本試験で使用した往復摺動試験機の全体図を示す. Fig.2 は試験機の摺動部のスケッチである. 試 験球には直径 $2 \mathrm{~mm}$ の超硬（WC）球を使用し，荷重（1N）はおもりを利用してWC 球に一定になるように 加えている. 摺動は, 試験片をステッピングモータで水平方向に往復運動させることで行なった. 摩擦力は 試験球側にひずみゲージの変位を読み取り, 出力電圧から摩擦力を求めた. 本研究では, 摺動距離 $2.5 \mathrm{~mm}$, 摺動速度約 $5 \mathrm{~mm} / \mathrm{s}$ とし，荷重 $1 \mathrm{~N}$ で摺動試験を行なった。

ニッケルめっき液はワールドメタル社のリンデン 506 を用い，DNP には Carbodeon 社のナノダイヤモン

\footnotetext{
${ }^{* 1}$ 学正員, 岡山大学 (T700-0080 岡山県 津島中 北区 3-1-1)

${ }^{* 2}$ 正員, 岡山大学 (T700-0080 岡山県 津島中 北区 3-1-1)

E-mail: en421041@s.okayama-u.ac.jp
}

[No.13-1] 日本機械学会 2013 年度年次大会講演論文集 [2013.9.8-11, 岡山] 
ドパウダー，試験片には炭素鋼 S50C（10mm×10mm）を使用した．めっきは，リンデン 506 を $\mathrm{pH} 4.9$, 温度 $363 \mathrm{~K}$ に調製し，2h 無電解ニッケルめっき処理を施すことによって行なった．複合膜の合成には，S50Cに 下地処理としてニッケルめっきを $30 \mathrm{~min}$ 施した後, 超音波洗浄を用いてめっき液中に DNP $0.01 \%$ 分散さ せ，同条件で複合めっき処理を $90 \mathrm{~min}$ 行なった．どちらもめっき処理後に $673 \mathrm{~K}$ で $2 \mathrm{~h}$ 熱処理を施した.

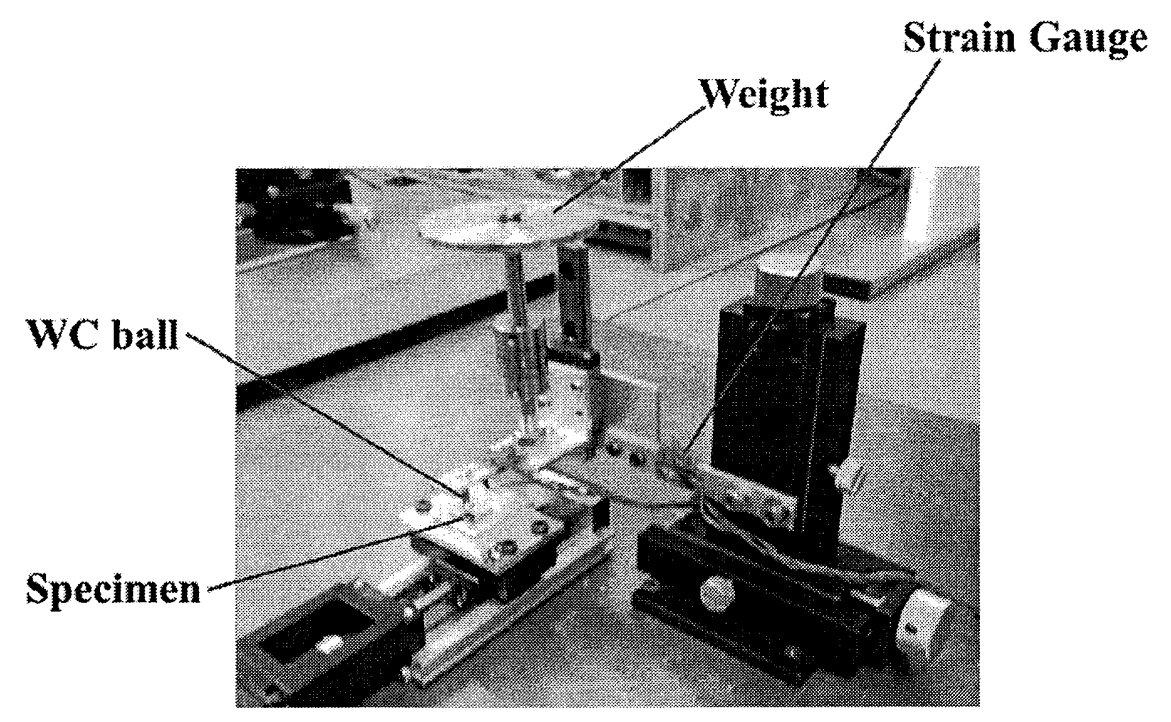

Fig.1 Photograph of Sliding Tester

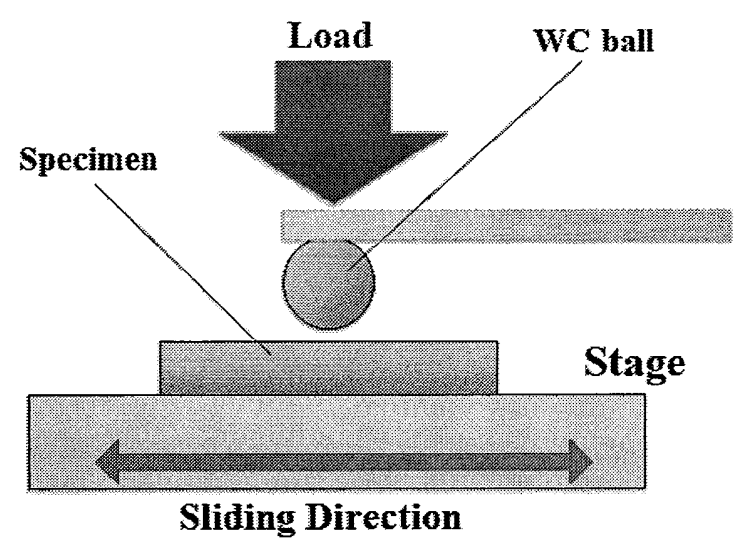

Fig.2 Schematic of Sliding Tester

\section{3. 摺動試験}

Fig.3 は本研究で行なった摩擦摺動試験の結果を示しており, 横軸が摺動回数 $(\mathrm{N})$, 縦軸が摩擦係数（ $\mu$ ）を

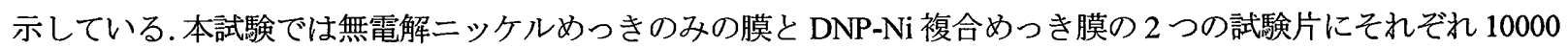
回の摺動試験を行った. Fig.3 (a)では, ニッケルめっきのみの膜に, 無潤滑, 水潤滑, DNP 分散水 (1wt.\%) の 3 条件で試験を行なった結果を示しており, Fig.3 (b)では DNP-Ni 複合めっき膜に同条件で試験を行なった結果を示 している.

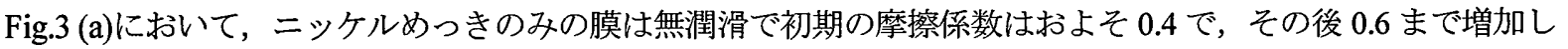
た. 水潤滑では初期の摩擦係数は 0.2 と低めだが, その後はしだいに増加し最終的にはおよそ 0.3 という值になっ た.これらに対し, DNP 分散水 (1wt.\%) では摺動回数およそ 1500 回までは変動し, 摩擦係数は最大で 0.4 まで 
高くなったが，その後は 0.2 の值で安定した.このように, ニッケルめっきのみの膜では無潤滑が最も摩擦保数 が高く, DNP 分散水による潤滑が 3 条件の中で最も低摩擦であることが分かった.
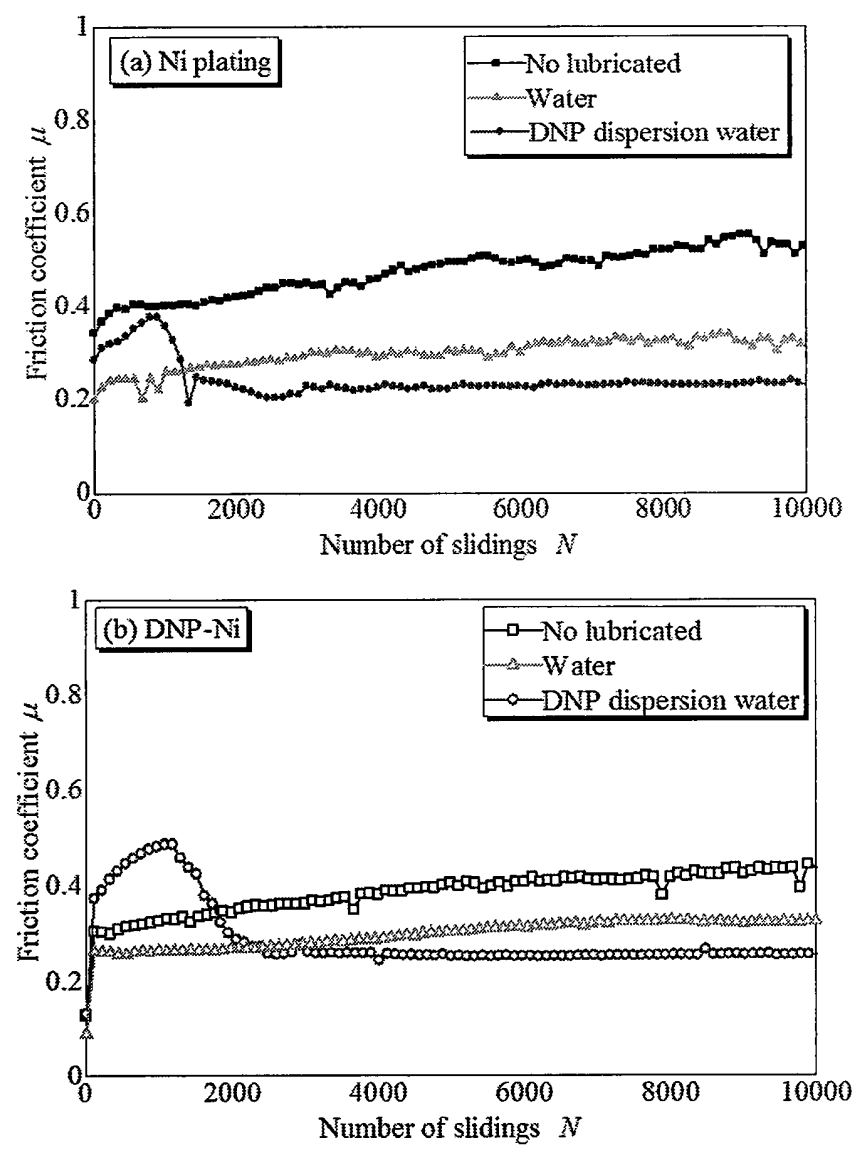

Fig.3 Friction coefficient of (a) electroless Ni plating and (b) electroless DNP-Ni plating

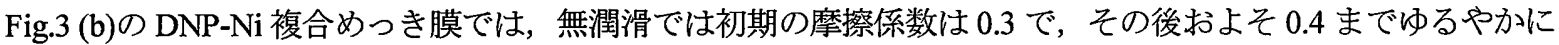
増加した．水潤滑では終始安定したおよそ 0.3 の值であった，そして，DNP 分散水ではニッケルめっき膜のもの と同様に, 初期は高い摩摖係数を示したが, 後に減少し摺動回数約 2000 回以降には摩擦係数は 0.2 であった. こ ちらもニッケルめっき膜と同様, 無潤滑での摩擦係数が最も高い值を示し, DNP 分散水による潤滑が最も低摩擦 であった。

これらの結果より，どちらの試験片も各潤滑条件では無潤滑が最も高い摩擦係数を示し，DNP 分散水 (1wt.\%) を潤滑材としたものが最も低い摩擦係数を示した．また，無潤滑ではニッケルめっきのみの膜に比べて DNP-Ni 複合めっき膜の方が低い摩擦係数を示したことから, DNP は無電解ニッケルめっき膜に複合させることで低摩擦 を実現できると考えられる.

\section{4. 試験後の表面観察}

Fig.4 は，(a) DNP-Ni 複合めっき膜の試験前の表面、（b）DNP-Ni 複合めっき膜を無潤滑で摺動したもの、(c) DNP 分散水 (1wt.\%) で潤滑し摺動した後の摺動痕をそれぞれ SEMによって観察したものである. 摺動前の DNP-Ni 複合めっき膜は表面において大きな凹凸が確認された．しかし，Fig.4（b）の画像より無潤滑で摺動した 複合めっき膜の表面からは凹凸が摩耗してなくなり平滑化されていることが分かった. それに対し Fig.4 (c) か らは，DNP 分散水（1wt.\%）による潤滑下において複合めっき膜は Fig.4（b）の摺動痕ほど大きな摩耗はしてお 
らず，摩耗は表面突起の一部にとどまっていることが分かった。これは水に分散させた DNPが潤滑材として作 用し，DNP が摺動中において摩耗を軽減するような働きをし, 結果として耐摩耗性を向上させたものと考えられ る.
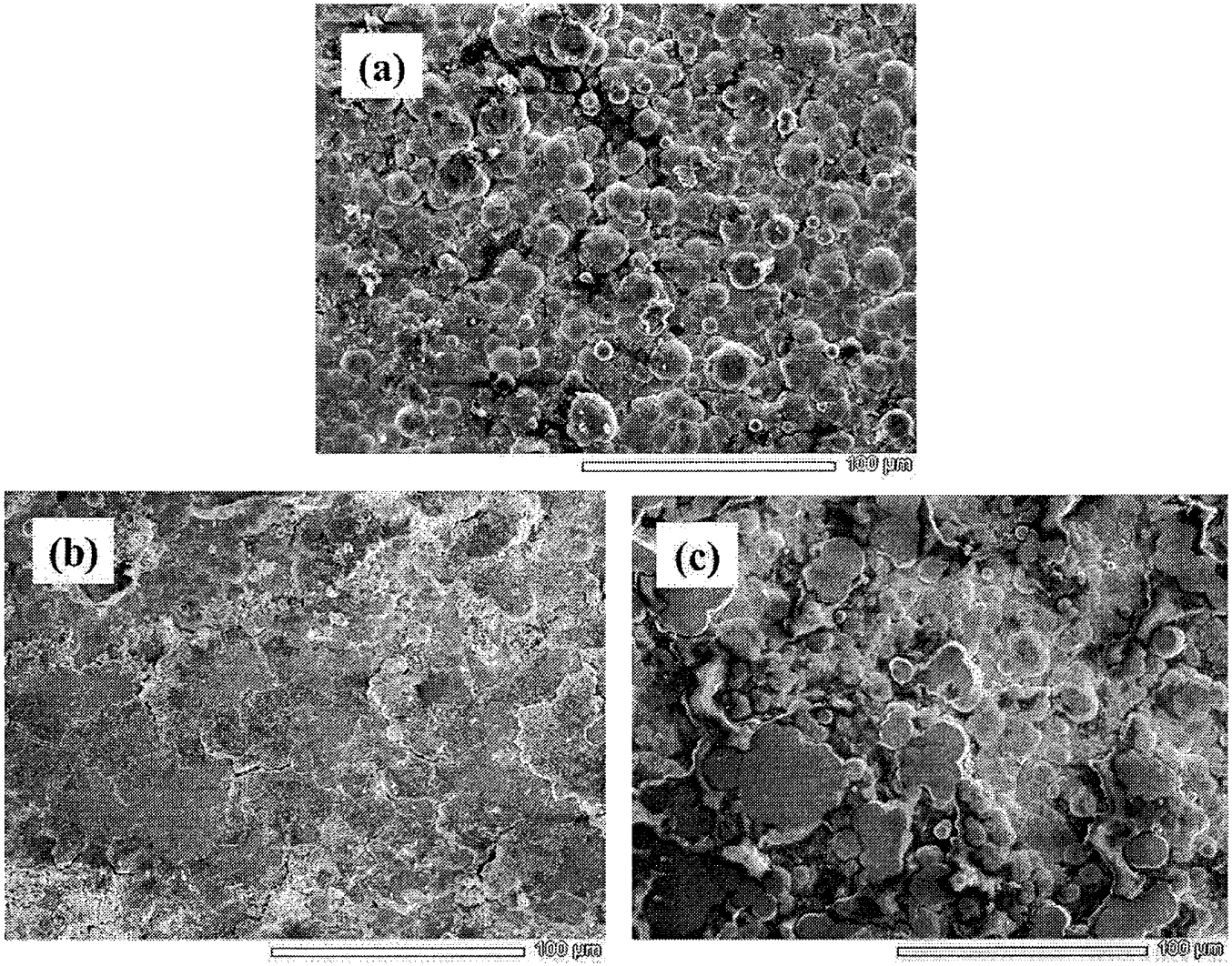

Fig.4 SEM representations of electroless DNP-Ni plating (a) at surface and the wear track under (b) no lubricant and (c) DNP dispersion water

\section{5. まとめ}

(1) DNP-Ni 複合めつき膜とニッケルめつき膜に, 無潤滑, 水潤滑, DNP 分散水による潤滑の 3 条件で試験を行 なった結果，どちらの試験片も摩擦係数は無潤滑で最も高く, 次いで水潤滑, そして DNP 分散水による潤 滑で最も低い值となった。

(2) 無潤滑において，ニッケルめつき膜の最終的な摩擦係数はおよそ 0.6, それに対して DNP-Ni 複合めっき膜 の摩擦係数はおよそ 0,4 ほどであった。

(3) 摺動後の SEM による表面観察より，DNP 分散水は摺動において耐摩耗性を向上させられる可能性がある.

文献

（1）田嶋和貴，無電解ニッケルめっき，表面技術協会，2010-02-01,p139-141

(2) Synthesis and properties of electroless Ni-P-Nanometer Diamond composite coatings, Surface \& Catings Technology 191 (2005) 161-165 